\title{
Electron field emission from excimer laser crystallized amorphous silicon
}

\author{
Y. F. Tang, S. R. P. Silva, ${ }^{\text {a) }}$ B. O. Boskovic, and J. M. Shannon \\ School of Electronics, Computing and Mathematics, University of Surrey, Guildford, \\ Surrey GU2 7XH, United Kingdom \\ M. J. Rose \\ Department of Electronic Engineering and Physics, University of Dundee, Dundee, United Kingdom
}

(Received 3 December 2001; accepted for publication 10 April 2002)

\begin{abstract}
We show field emission from excimer laser crystallized (ELC) hydrogenated amorphous silicon $(a-\mathrm{Si}: \mathrm{H})$ at current densities and threshold fields suitable for display applications. The laser crystallized $a$-Si:H gives rise to a densely packed and relative sharp surface morphology that gives emission currents of the order of $10^{-5} \mathrm{~A}$ (current densities $\approx 0.04 \mathrm{~A} / \mathrm{cm}^{2}$ ) at threshold fields less than $15 \mathrm{~V} / \mu \mathrm{m}$ in a diode configuration, without the need for a forming process. With the progress in utilizing ELC in flat panel driver electronics, a fully integrated field emission display on a single glass substrate can now be envisaged. (c) 2002 American Institute of Physics. [DOI: $10.1063 / 1.1482141]$
\end{abstract}

Field emission from single crystal silicon $(c-\mathrm{Si})$ microtips has been widely researched since Fraser's first report in $1973 .{ }^{1}$ However, due to uniformity issues associated with large area lithography and the expense involved in such a process, the prospective use of silicon $(\mathrm{Si})$ for field emission applications has not made much progress. Furthermore, $c-\mathrm{Si}$ has size restrictions imposed by wafer manufacturability and large area displays are not feasible with such a technology. Since then flat emitter materials such as diamond, ${ }^{2}$ amorphous carbon ${ }^{3}$ ( $a$-C), $a$-Si: $\mathrm{H}^{4}{ }^{4}$ polycrystalline silicon, ${ }^{5,7}$ (poly-Si) and silicon nanowires ${ }^{6}$ have shown a wide range of possibilities for using thin film technology as cold cathodes. However, these flat films do not benefit from external geometric enhancement as compared to those with tip structures. The field emission from $a$-Si is not fully understood and poly-Si deposited by low-pressure chemical vapor deposition (LPCVD) does not give uniform emission site densities. ${ }^{7} \mathrm{Al}-$ though poly-Si deposited by LPCVD could produce tip structures through photolithographic processes, its large grain boundaries prevent the forming of uniform sharp tip structures. ${ }^{8}$ Silicon, especially the amorphous and polycrystalline forms are the preferred choice for the display industries as it is well established and forms the basis of a proven large area technology. It could readily be integrated into the present driver circuits and it is cheap to manufacture with existing technologies with large area displays being feasible.

In this letter, we report on the electron field emission results obtained from laser crystallized $\mathrm{Si}$. A study of these crystallized structures has led us to a possible explanation of the emission process with an internal field being a major driving force for emission of electrons under high fields.

The $a$-Si:H films were deposited at a thickness of 100 nm using a standard plasma enhance chemical vapor deposition (PECVD) system with feed gases of silane $\left(\mathrm{SiH}_{4}\right)$ and hydrogen $\left(\mathrm{H}_{2}\right)$. The films were undoped, and deposited on glass substrates coated with a continuous molybdenum (Mo) film of $100 \mathrm{~nm}$ thickness. An excimer $\mathrm{KrF}$ laser $(248 \mathrm{~nm}$

\footnotetext{
a) Author to whom correspondence should be addressed; electronic mail: s.silva@surrey.ac.uk
}

wavelength) was used to irradiate the $a$-Si:H samples with a scan rate of $2 \mathrm{~mm} / \mathrm{s}$ over the length of the sample to produce a strip of width $4 \mathrm{~mm}$. The process was carried out in air. Strips of crystallized silicon regions with energy densities of $179,204,221,235,241$, and $263 \mathrm{~mJ} / \mathrm{cm}^{2}$ were used in our investigation. The fabrication process is scalable to larger areas compatible with displays of dimensions $1 \mathrm{~m} \times 1 \mathrm{~m}$.

For field emission measurements a spherical stainless steel anode, $5 \mathrm{~mm}$ in diameter, was placed above the cathode surface, which was greater than $20 \mathrm{~mm} \times 20 \mathrm{~mm}$ in area, by means of a micrometer controlled apparatus. The emission current ( $I$ in amps) versus macroscopic electric field ( $E$ in $\mathrm{V} / \mu \mathrm{m})$ characteristics was obtained at a vacuum better than $5 \times 10^{-6}$ mbar. The macroscopic field used to plot the characteristics was simply the applied voltage (V) divided by the vacuum gap $(\mu \mathrm{m})$. Each current reading was recorded only when a stable applied voltage was detected. The recorded value is taken from an average of a hundred readings. The applied voltage was incremented in $15 \mathrm{~V}$ steps from 50 to $2000 \mathrm{~V}$, with a current limit set at $1 \times 10^{-5} \mathrm{~A}$. The field emission threshold was defined when the emission current reached $1 \times 10^{-9} \mathrm{~A}$ at a particular electric field. The numbers of field emission data points shown in the plots have been greatly reduced for clarity.

The excimer laser was used to irradiate a total substrate area which was $75 \mathrm{~mm} \times 75 \mathrm{~mm}$ square in $4 \mathrm{~mm} \times 70 \mathrm{~mm}$ strips with different energy densities and each area tested for its field emission properties. The electron field emission obtained for the different energy density treated films is shown in Fig. 1(a). The rate of change in the gradient of the slopes is different for each film. It shows the steepest slope and lowest emission threshold is from the film with an area irradiated by an energy density of $204 \mathrm{~mJ} / \mathrm{cm}^{2}$. When the emission area from this film was imaged using a commercial phosphor screen at $30 \mathrm{~V} / \mu \mathrm{m}$, the site density coverage was in excess of $80 \%$. Individual emission sites could not be imaged, as the emission observed was uniformly bright throughout except for 2 or 3 very high brightness regions. These results point toward the film irradiated with 204 $\mathrm{mJ} / \mathrm{cm}^{2}$ having the most uniform and best threshold field. A 

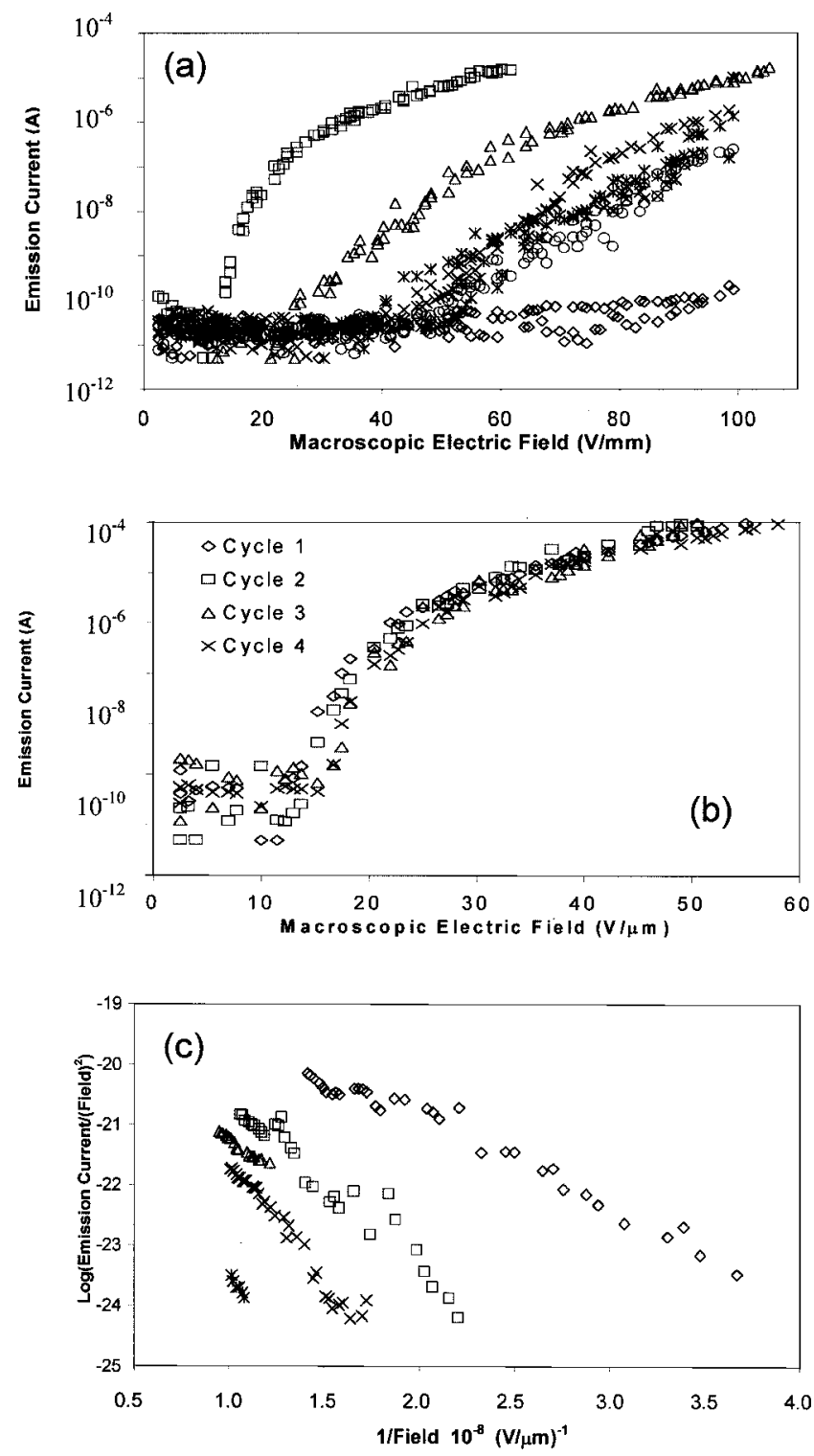

FIG. 1. (a) Emission current as a function of macroscopic electric field for $a$-Si:H films treated with excimer laser energy densities of $179 \mathrm{~mJ} / \mathrm{cm}^{2}(\diamond)$, $\left.204 \mathrm{~mJ} / \mathrm{cm}^{2}(\square), 221 \mathrm{~mJ} / \mathrm{cm}^{2}(\triangle), 235 \mathrm{~mJ} / \mathrm{cm}^{2}(\times), 241 \mathrm{~mJ} / \mathrm{cm}^{2}{ }^{*}\right)$ and 263 $\mathrm{mJ} / \mathrm{cm}^{2}(\mathrm{O})$. (b) Current-field characteristic for the film treated with an energy density of $204 \mathrm{~mJ} / \mathrm{cm}^{2}$ with four emission cycles showing the absence of a conditioning phase or any significant hysteresis; (c) the FowlerNordheim plot for the data in (a).

stable and reproducible emission from the irradiated surface with the laser energy density of $204 \mathrm{~mJ} / \mathrm{cm}^{2}$ with no evidence of conditioning or hysteresis is shown in Fig. 1(b). ${ }^{9}$ Emission observed from unconditioned flat $a-\mathrm{Si}: \mathrm{H}$ films is associated with a large hysteresis and an initiation field which is always required before stable emission is obtained. ${ }^{4}$ The Fowler-Nordhiem (F-N) plot for the data in Fig. 1(a) is shown in Fig. 1(c). The relatively straight-line plots may at first sight suggest that the electron emission is controlled by a quantum mechanical tunneling process. ${ }^{6}$ The enhancement factor $\beta$ calculated from the $\mathrm{F}-\mathrm{N}$ plots, taking the silicon work function to be $3.6 \mathrm{eV}$, is found to be 467 , with a field emission threshold of $15 \mathrm{~V} / \mu \mathrm{m}$ for the film treated at 204 $\mathrm{mJ} / \mathrm{cm}^{2}$. This value is very similar to those reported for silicon nanowires, ${ }^{6}$ despite the physical and microstructure being completely different. A closer examination of the data shows a nonlinear curve, which has been seen and reported
TABLE I. Measured and calculated field emission properties for the excimer laser treated $a$-Si:H films.

\begin{tabular}{llllll}
\hline \hline $\begin{array}{l}\text { Energy density }\left(\mathrm{mJ} / \mathrm{cm}^{2}\right) \\
\text { Calculated } \beta \text { factor from } \\
\text { the } \mathrm{F}-\mathrm{N} \text { plot (work } \\
\text { function }=3.69 \mathrm{eV})\end{array}$ & 204 & 221 & 235 & 241 & 263 \\
$\begin{array}{l}\text { Calculated emission area } \\
\times\left(10^{-13} \mathrm{~cm}^{2}\right)\end{array}$ & 2.2 & 2.0 & 2.7 & 5.3 & 8.3 \\
$\begin{array}{l}\text { Width of the tip }(\mu \mathrm{m}) \\
\text { Height of the tip }(\mu \mathrm{m})\end{array}$ & 0.12 & 0.18 & 0.12 & 0.18 & 0.18 \\
$\begin{array}{l}\text { Calculated } \beta \text { factor with } \\
h / w \text { (Ref. } 16)\end{array}$ & 2.75 & 0.45 & 0.45 & 0.43 & 0.34 \\
$\begin{array}{l}\text { Ratio difference between } \\
\text { the apparent and actual } \\
\text { physical } \beta \text { factors }\end{array}$ & 176 & 64 & 6.75 & 2.38 & 1.89 \\
\hline
\end{tabular}

by others working on graphite nanofibers ${ }^{10}$ and multiwalled carbon nanotubes. ${ }^{11,12}$ This may be attributed to nonuniformity in the emission surface. The less sharp tips would emit only when the electric field is high enough to be able to sustain the increasing emission current. If a FowlerNordheim-type emission mechanism is assumed, $\beta$ factors calculated using the best computer fit are shown in Table I, using a work function of $3.59 \mathrm{eV} .^{13}$

Changes to the surface morphology due to the laser crystallization was examined using a field emission gun scanning electron microscope (FEG-SEM) and is shown in Fig. 2. Relatively sharp tips are observed on the surface created during the laser crystallization process, which has been well documented. ${ }^{14}$ The initial comparison between measured field emission enhancement factors in Table I and the structure from SEM micrographs in Fig. 2 shows some correla-
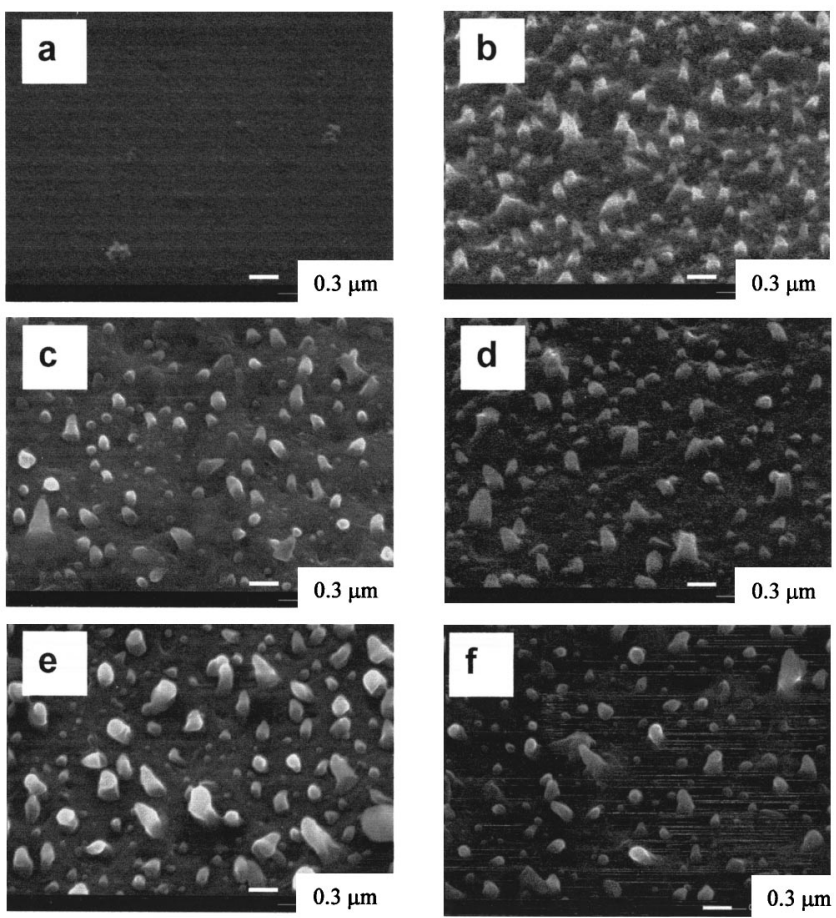

FIG. 2. SEM micrograph taken with the sample tilted at $45^{\circ}$ to the plane for films treated with energy densities of (a) $179 \mathrm{~mJ} / \mathrm{cm}^{2}$, (b) $204 \mathrm{~mJ} / \mathrm{cm}^{2}$, (c) $221 \mathrm{~mJ} / \mathrm{cm}^{2}$, (d) $235 \mathrm{~mJ} / \mathrm{cm}^{2}$, (e) $241 \mathrm{~mJ} / \mathrm{cm}^{2}$, and (f) $263 \mathrm{~mJ} / \mathrm{cm}^{2}$. 


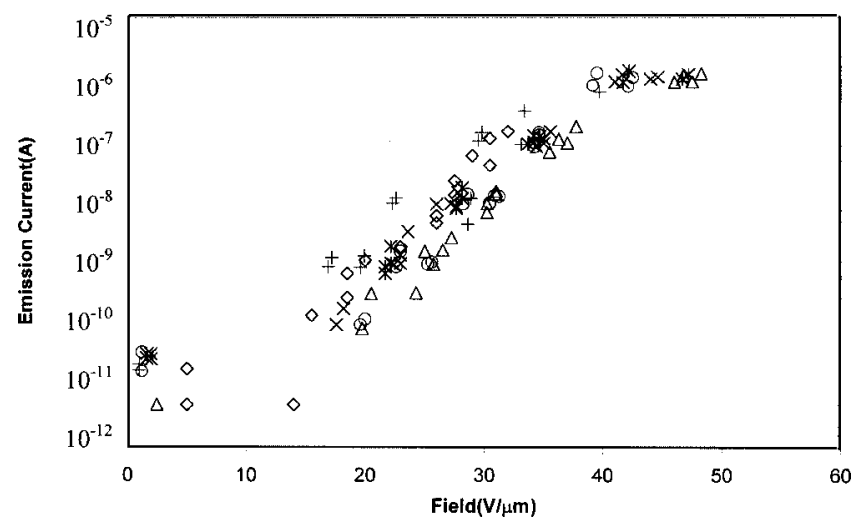

FIG. 3. Field emission for films treated with a laser energy density of 204 $\mathrm{mJ} / \mathrm{cm}^{2}$ for vacuum gaps of $10 \mu \mathrm{m}(\diamond), 20 \mu \mathrm{m}(\square), 25 \mu \mathrm{m}(\triangle), 30 \mu \mathrm{m}$ $(\times), 40 \mu \mathrm{m}(*)$, and $50 \mu \mathrm{m}(\bigcirc)$ vs macroscopic electric field.

tion. The dense and relatively sharp tips created using an energy density of $204 \mathrm{~mJ} / \mathrm{cm}^{2}$ improves the geometrical $\beta$ factor for field emission from the crystallized $a-\mathrm{Si}: \mathrm{H}$ film. However, the enhancement factor based on geometric considerations is still only 3 . The high density of emission sites is clearly visible when the phosphor screen is used to compare images obtained from $204 \mathrm{~mJ} / \mathrm{cm}^{2}$ with other laser energies.

The field emission data shown in Fig. 3 is taken from the sample irradiated with an energy density of $204 \mathrm{~mJ} / \mathrm{cm}^{2}$, for different vacuum gaps. It shows the emission process to be largely independent of the anode to cathode distance, and to be related only to the applied field. The independence of the field emission threshold with vacuum gap may at first sight suggest that bulk material properties and space charge does not take part in the field emission process.

From Table I it is clear that the geometric enhancement $\beta$ factor does play a role in this field emission process. However, it may not be the only or main factor that controls the low threshold emission, as there are large discrepancies between the $\beta$ factor calculated from the $\mathrm{F}-\mathrm{N}$ plot and the $\beta$ factor calculated from the estimated height $(h)$ and radius $(r)$ of the tips from the SEM micrographs using the formula, ${ }^{15}$ $\beta=h / r$. The ratio is based on the tallest average tips (ignoring the short tips), as the emission will be dominated by these features, and the height is obtained from the SEM image with the sample with the highest $\beta$ factor tilted at $45^{\circ}$. The width is taken directly from the plane view SEM. Oval features are ignored in the calculation as these tips will be slanted and thereby have lower $\beta$ factors. The $\beta$ factor that is calculated from the electrically controlled $\mathrm{F}-\mathrm{N}$ plot has a much higher value, as shown in Table I. The ratio difference between the two $\beta$ values shows a large step for the sample irradiated with $204 \mathrm{~mJ} / \mathrm{cm}^{2}$. This result suggests an internal field enhancement process dominated by the material properties has greatly enhanced the emission, which results in the large difference between the two $\beta$ factors. Furthermore, the emission area that is calculated from the $\mathrm{F}-\mathrm{N}$ plot shown in Table I is unrealistically small.

To understand this field emission mechanism in more detail, a transmission electron microscope (TEM) was employed to study the structure of the material following irradiation at $204 \mathrm{~mJ} / \mathrm{cm}^{2}$. The resulting cross sectional analysis shows strong evidence of columnar growth that is common in laser crystallized $\mathrm{Si}^{14}$ However, the diffraction pattern shows different crystal orientations and a diffuse ring indicating the material to be more microcrystalline in nature as opposed to polycrystalline. An analysis of the cross section of the excimer laser crystallized Si gives a microstructure composed of columnar $\mathrm{Si}$ nanocrystals around $90 \mathrm{~nm}$ in height and around $50 \mathrm{~nm}$ in diameter, surrounded by grain boundaries. A recent paper by Carey et al. ${ }^{16}$ suggests that internal field enhancements between 50 and 200 can be obtained purely due to proximity effects of conducting spheres, when placed within a dielectrically inhomogeneous medium. The mixed-phase crystallites to grain boundary ratio observed in these samples might give rise to such a phenomenon that allows for the high fields to be generated. This would then allow for hot electrons to be generated within the laser crystallized materials which aid electron emission into vacuum.

Electron field emission at low threshold fields from ELC silicon is a very exciting result and we have demonstrated emission threshold (less than $15 \mathrm{~V} / \mu \mathrm{m}$ ) which are comparable to those reported for $\mathrm{Si}$ nanowires ${ }^{6}(15 \mathrm{~V} / \mu \mathrm{m})$, to those observed from poly-Si by LPCVD with oxidation sharpening $^{7}$ and poly-Si microtip ${ }^{8}(20 \mathrm{~V} / \mu \mathrm{m})$, to those of single $c$-Si microtip ${ }^{17}(20 \mathrm{~V} / \mu \mathrm{m})$. Furthermore, the technologies that are discussed in this letter are all mature technologies in the display sector, and could readily be incorporated into a working device.

The authors would like to thank D. J. McCulloch of Philips Research Laboratories, Redhill (UK) for help with laser irradiations.

${ }^{1}$ D. L. Fraser, U.S. Patent No. 3, 753, 022 (1973).

${ }^{2}$ M. W. Geis, N. N. Efremow, K. E. Krohn, J. C. Twichell, T. M. Lyszczarz, R. Kalish, J. A. Greer, and M. D. Tabat, Nature (London) 393, 431 (1998).

${ }^{3}$ G. A. J. Amaratunga and S. R. P. Silva, Appl. Phys. Lett. 68, 2529 (1996).

${ }^{4}$ S. R. P. Silva, R. D. Forrest, and J. M. Shannon, J. Non-Cryst. Solids 227, 1101 (1998).

${ }^{5}$ K. K. Vossough and R. W. Bower, J. Vac. Sci. Technol. B 18, 962 (2000).

${ }^{6}$ F. C. K. Au, K. W. Wong, Y. H. Tang, Y. F. Zhang, I. Bello, and S. T. Lee, Appl. Phys. Lett. 75, 1700 (1999).

${ }^{7}$ A. A. Evtukh, Thin Solid Films 337, 261 (1999).

${ }^{8}$ S. E. Huq, G. H. Grayer, and P. D. Prewett, J. Vac. Sci. Technol. B 15, 2855 (1997).

${ }^{9}$ J. D. Carey and S. R. P. Silva, Appl. Phys. Lett. 78, 347 (2001).

${ }^{10}$ Y. Chen, S. Patel, Y. Ye, D. T. Shaw, and L. Guo, Appl. Phys. Lett. 73, 2119 (1998).

${ }^{11}$ M. J. Fransen, T. L. V. Rooy, and P. Kruit, Appl. Surf. Sci. 146, 312 (1999).

${ }^{12}$ M. Stammler, J. Ristin, T. Habermann, A. Gohl, K. Janischowsky, D. Nau, G. Muller, and L. Ley, Diamond Relat. Mater. 8, 792 (1999).

${ }^{13}$ A. Braun and G. Busch, Helv. Phys. Acta 20, 33 (1947).

${ }^{14}$ D. J. McCulloch and S. D. Brotherton, Appl. Phys. Lett. 66, 2060 (1995).

${ }^{15}$ G. Vibrans, MIT Lincoln Laboratory Report No. 353, 1964 (unpublished).

${ }^{16}$ J. D. Carey, R. D. Forrest, and S. R. P. Silva, Appl. Phys. Lett. 78, 2339 (2001).

${ }^{17}$ T. Sugino, S. Kawasaki, K. Tanioka, and J. Shirafuji, Appl. Phys. Lett. 71, 2704 (1997). 